\title{
Echo is the preferred modality for hemodynamic monitoring in the cardiac intensive care unit
}

\author{
Hillel A. Steiner ${ }^{*}$, Yonatan Hasin \\ Division of Cardiovascular Medicine, Boruch Padeh Medical Center, Lower Galilee, Israel \\ Email: *hsteiner@poria.health.gov.il
}

Received 7 March 2012; revised 9 April 2012; accepted 18 April 2012

\begin{abstract}
The PAC has enabled major advances in understanding cardiac hemodynamics and pathophysiology. However its clinical utility is limited by data interpretation and serious complications. Echocardiography provides a useful alternative for hemodynamic assessment as well as identification of important concomitant findings. The combination of echocardiography with insertion of a central venous pressure catheter may be the optimal combination for hemodynamic monitoring.
\end{abstract}

Keywords: Hemodynamics; Pulmonary Artery Catheter; Echocardiography

\section{INTRODUCTION}

The pulmonary artery catheter (PAC) was developed to measure pressures, blood flow and oxygen saturation in the right heart. Although it is an important diagnostic tool in a wide variety of respiratory and circulatory conditions, it has serious limitations and its clinical utility remains unproven.

The feasibility of PAC use was first shown by Dr. Warner Forssman in 1929, when he threaded a catheter into his own heart [1], for which he shared the 1956 Nobel Prize along with Drs. Richards and Cournand. Bedside use was facilitated by the addition of a flow directed balloon to the catheter by Dr. Swan, and a thermistor tip by Dr. Ganz which enabled measurement of cardiac output [2]. Many classical studies were enabled by the use of the PAC such as the Forrester classification of acute heart failure to improve assessment of the risk of mortality in myocardial infarction [3,4], as well as the identification of complications of myocardial infarction such as acute mitral incompetence and ventricular septal rupture. The utility of pharmacological interventions as in the effect of furosemide [5] and nesiritide in pulmonary edema [6] as well as the efficacy of nitroprusside in acute mitral regurgitation [7] were enabled by the PAC.

\footnotetext{
${ }^{*}$ Corresponding author.
}

\section{UTILITY OF THE PAC}

With the PAC, pressures in the right atrium, right ventricle and pulmonary artery could be measured directly. With blood sampling for oxygen saturation, the cardiac output can be calculated using Fick's formula as well as the location and fraction of right to left shunts. With the inflation of the pulmonary catheter balloon, pressure of pulmonary microvasculature may be measured-an approximation of the left atrial pressure and left ventricular end diastolic pressure (LVEDP). The cardiac output is estimated by injection of cold saline from the proximal port and temperature measurement at the distal port.

\section{PITFALLS AND PROBLEMS OF THE PAC}

However, there are important exceptions and limitations to this approximation. Accurate measurement of pressures may be exceedingly difficult due to respiratory excursion. Placement of the PAC in the upper lung fields, in which the alveolar pressure is greater than the capillary blood pressure, may cause an overestimation of the pulmonary capillary pressure by the pulmonary arterial occlusion pressure (PAOP). Veno-occlusive and mitral valve disease will create a pressure gradient between the capillaries and the left atrium, or between the left atrium and ventricle respectively. The relationship between the PAOP and the left ventricular end diastolic pressure is non-linear, the PAOP does not follow the late pressure rise due to atrial contraction. Furthermore, the left ventricular compliance can change rapidly and pericardial pressures will influence the LVEDP but not the PCWP. Thus, use of the PAOP to estimate preload responsiveness at any given time has serious limitations. Accuracy of the measurement of the cardiac output may be flawed due to tricuspid regurgitation or inaccuracy of the volume injected.

The list of possible complications caused by PAC insertion is extensive. Hemorrhage, pneumothorax, damage to valves, arrhythmias, conduction disturbances, perforation of the right ventricle or pulmonary artery, all 
may be life threatening. The indwelling catheter may become infected and cause sepsis or endocarditis. The catheter can obstruct a pulmonary artery and cause a pulmonary infarction [8].

\section{EVIDENCE-BASED MEDICINE AND THE PAC}

It is thus not surprising that large randomized trials have not shown a clinical benefit with use of the PAC. The Canadian Critical Care group randomized 1994 high risk surgical patients to use of PACs, and there was no difference in mortality realized between the two groups [9]. In a French study 686 patients with adult respiratory distress syndrome or shock were randomized to use or nonuse of PACs and there was no reduction in mortality, length of hospital stay and freedom from organ failure between the groups [10]. The PAC has not been useful in other critically ill patients. The English Pac-Man trial randomized 1014 patients with multi organ failure to use or non-use of PACs with no difference demonstrated in mortality or length of hospital stay [11]. In the FACTT trial 1000 patients with ARDS were randomized to use of PACs. Fluid resuscitation was dictated by protocol. There were more complications with PACs without any survival benefit [12]. In the ESCAPE trial 415 patients with severe heart failure were randomized to use of PAC-guided treatment. There was no difference in survival or length of hospitalization with PACs. The PACs were associated with $21 \%$ adverse event and $12 \%$ infection rate [13]. Use of PACS has not been proven to improve any patient subset (Table 1).

\section{ECHOCARDIOGRAPHY-THE ALTERNATIVE FOR HEMODYNAMIC MEASUREMENTS}

Fortunately, a better alternative to PAC use is readily available. Echocardiography can provide the hemodynamic measurements non-invasively. Right sided pressures may be estimated by use of inferior vena cava size, tricuspid valve and pulmonic valve gradients. The aortic flow integral approximates the cardiac output [14]. The LVEDP may be assessed via tissue Doppler measurement of the $\mathrm{E} / \mathrm{E}$ ' ratio [15] or by measurement of the velocity of the jet of aortic or pulmonary regurgitation. Critical concomitant findings may be noted during hemodynamic assessment including cardiac tamponade, pulmonary embolism or valvular pathology [16].

Even in the hands of the less experienced, echocardiography remains a useful tool. In one study, ICU residents were given a short 8 hour course limited to interpretation of LV size and function, RV dilation, pericardial effusion, and pleural effusion. The residents were then able to evaluate $93 \%$ of 366 clinical questions with
Table 1. Relative advantages and disadvantages of methods for hemodynamic monitoring.

\begin{tabular}{ll}
\hline Pulmonary artery catheter & Echocardiography \\
\hline Advantages: & Advantages: \\
Continuous real time measurement & Non-invasive \\
Disadvantages: & Disadvantages: \\
Inaccuracies in measurements & $\begin{array}{l}\text { Requires multiple studies } \\
\text { (i.e. catheter placement in upper } \\
\text { lung fields, venous occlusive } \\
\text { disease, tricuspid regurgitation) }\end{array}$ \\
$\begin{array}{l}\text { Complications of insertion } \\
\text { (i.e. pneumothorax, hemothorax, }\end{array}$ & \\
arrhythmias) & \\
$\begin{array}{l}\text { Complications of continued use } \\
\text { (i.e. sepsis, pulmonary infarction) }\end{array}$ & \\
\hline
\end{tabular}

close agreement with the interpretation of expert operators [17]. In a similar study, intensivists were given a ten hour course in echo after which they performed handheld bedside examinations. Their interpretations correlated well with those of experienced echocardiographers in $84 \%$ of the examinations and led to treatment adjustments in $37 \%$ of the subjects [18]. Echocardiography can be widely used.

The one pitfall of echocardiographic hemodynamic assessment lies in the estimation of right atrial pressure. The size and compressibility of the inferior vena cava has been suggested however this may be hard to quantify, and is inaccurate in mechanically ventilated patients [19]. We suggest a hybrid approach, in which a central venous pressure catheter could be used to provide the right atrial pressure supplementing the echocardiographic study. This approach may avoid many of the serious complications of manipulation of the PAC through the right heart, while allowing accurate right atrial pressure measurement. Furthermore, this enables central venous blood saturation sampling, which may give complementary data regarding hemodynamic status.

In conclusion, the PAC has enabled major advances in understanding cardiac hemodynamics and pathophysiology. However its clinical utility is limited by data interpretation and serious complications. Echocardiography provides a useful and safe alternative for hemodynamic assessment which can also identify important concomitant findings. The addition of a central venous catheter will increase the accuracy of the echocardiographic study while avoiding many of the complications of PACs.

\section{REFERENCES}

[1] Forssmann, W. (1929) Die sondierung des rechten herzens. Klin Wochenschr, 8, 2089. doi:10.1007/BF01875120

[2] Swan, H.J., Ganz, W., Forrester, J., et al. (1970) Catheterization of the heart in man with use of a flow-directed 
balloon-tipped catheter. The New England Journal of Medicine, 283, 447-451.

doi:10.1056/NEJM197008272830902

[3] Forrester, J.S., Diamond, G., Chatterjee, K., et al. (1976) Medical therapy of acute myocardial infarction by application of hemodynamic subsets (first of two parts). The New England Journal of Medicine, 295, 1356-1362. doi:10.1056/NEJM197612092952406

[4] Forrester, J.S., Diamond, G., Chatterjee, K., et al. (1976) Medical therapy of acute myocardial infarction by application of hemodynamic subsets (second of two parts). The New England Journal of Medicine, 295, 1404-1413. doi:10.1056/NEJM197612162952505

[5] Dikshit, K., Vyden, J.K., Forrester, J.S., et al. (1973) Renal and extrarenal hemodynamic effects of furosemide in congestive heart failure after acute myocardial infarction. The New England Journal of Medicine, 288, 1087-1090. doi:10.1056/NEJM197305242882102

[6] Elkayam, U., Akhter, M.W., Singh, H., et al. (2004) Comparison of effects on left ventricular filling pressure of intravenous nesiritide and high-dose nitroglycerin in patients with decompensated heart failure. The American Journal of Cardiology, 93, 237-240. doi:10.1016/j.amjcard.2003.09.051

[7] Chatterjee, K., Parmley, W.W., Swan, H.J., et al. (1973) Beneficial effects of vasodilator agents in severe mitral regurgitation due to dysfunction of subvalvar apparatus. Circulation, 48, 684-690. doi:10.1161/01.CIR.48.4.684

[8] Hadian, M. and Pinsky, M.R. (2006) Evidence-based review of the use of the pulmonary artery catheter: Impact data and complications. Critical Care, 10, S8. doi:10.1186/cc4834

[9] Herridge, M.S., Cheung, A.M., Tansey, C.M., et al. (2003) One-year outcomes in survivors of the acute respiratory distress syndrome. The New England Journal of Medicine, 348, 683-693. doi:10.1056/NEJMoa022450

[10] Richard, C., Warszawski, J., Anguel, N., et al. (2003) Early use of the pulmonary artery catheter and outcomes in patients with shock and acute respiratory distress syndrome: A randomized controlled trial. Journal of the American Medical Association, 290, 2713-2720. doi:10.1001/jama.290.20.2713

[11] Harvey, S., Harrison, D.A., Singer, M., et al. (2005) Assessment of the clinical effectiveness of pulmonary artery catheters in management of patients in intensive care
(PAC-Man): A randomised controlled trial. Lancet, 366, 472-477. doi:10.1016/S0140-6736(05)67061-4

[12] Wheeler, A.P., Bernard, G.R., Thompson, B.T., et al. (2006) Pulmonary-artery versus central venous catheter to guide treatment of acute lung injury. The New England Journal of Medicine, 354, 2213-2224. doi:10.1056/NEJMoa061895

[13] Binanay, C., Califf, R.M., Hasselblad, V., et al. (2005) Evaluation study of congestive heart failure and pulmonary artery catheterization effectiveness: The ESCAPE trial. Journal of the American Medical Association, 294, 1625-1633. doi:10.1001/jama.294.13.1625

[14] Stein, J.H., Neumann, A., Preston, L.M., et al. (1997) Echocardiography for hemodynamic assessment of patients with advanced heart failure and potential heart transplant recipients. Journal of the American College of Cardiology, 30, 1765-1772. doi:10.1016/S0735-1097(97)00384-7

[15] Nagueh, S.F., Middleton, K.J., Kopelen, H.A., et al. (1997) Doppler tissue imaging: A noninvasive technique for evaluation of left ventricular relaxation and estimation of filling pressures. Journal of the American College of Cardiology, 30, 1527-1533. doi:10.1016/S0735-1097(97)00344-6

[16] Griffee, M.J., Merkel, M.J. and Wei, K.S. (2010) The role of echocardiography in hemodynamic assessment of septic shock. Critical Care Clinics, 26, 365-382. doi:10.1016/j.ccc.2010.01.001

[17] Vignon, P., Dugard, A., Abraham, J., et al. (2007) Focused training for goal-oriented hand-held echocardiography performed by noncardiologist residents in the intensive care unit. Intensive Care Medicine, 33, 17951799. doi:10.1007/s00134-007-0742-8

[18] Manasia, A.R., Nagaraj, H.M., Kodali, R.B., et al. (2005) Feasibility and potential clinical utility of goal-directed transthoracic echocardiography performed by noncardiologist intensivists using a small hand-carried device (SonoHeart) in critically ill patients. Journal of Cardiothoracic and Vascular Anesthesia, 19, 155-159. doi:10.1053/j.jvca.2005.01.023

[19] Jue, J., Chung, W. and Schiller, N.B. (1992) Does inferior vena cava size predict right atrial pressures in patients receiving mechanical ventilation? Journal of the American Society of Echocardiography, 5, 613-619. 